\title{
An Overview: Children's Literature, Its Development and Translation in China
}

Min GAO

\begin{abstract}
Although children's literature has long been in a peripheral position compared with adult literature across the world, it is emerging in the book market of China in the past ten years, when large amounts of children's picture books were imported and translated every year from other languages. Interestingly, over $90 \%$ of the existing children's picture books in the Chinese book market were translated instead of being domestically created. This article provides an overview of the children's literature, its development and translations in China. Problems are identified concerning the translation to offer further suggestions for the translated children's literature in China in the future ${ }^{1}$.
\end{abstract}

Keywords: Children's Literature, Translation, Development, Problems.

\section{Introduction}

Although children's literature has long been in a peripheral position compared with adult literature across the world, it is emerging in the book market of China in the past ten years, when large amounts of children's picture books were imported and translated every year from other languages. Interestingly, over 90\% of the existing children's picture books in the Chinese book market were translated instead of being

1 Acknowledgement: I would like to express my thanks to Dr. Tarek Shammaand Dr. Song Chenqingat the TRIP program for their valuable suggestions concerning the paper. 
domestically created. This article provides an overview of the children's literature, its development and translations in China. Problems are identified concerning the translation to offer further suggestions for the translated children's literature in China in the future.

\section{The Peripheral Position of Children's Literature}

Children's literature (hereinafter referred to as CL) has long been in a peripheral position compared with that of the adult literature. In 2003, Zohar Shavit, an internationally renowned scholar on the child and youth culture, expressed her concern over the unsatisfactory status quo of children's literature. She pointed out that the study of children's literature was regarded as an insignificant research field and suffered from a status of inferiority. Children's literature is not only peripheral in the poly-cultural system, but in the field of translation studies. There is far less research on the study of children's literature in contrast to other topics such as translation theory, translation pedagogy, translator training etc. Scholars have noticed the phenomenon. For example, Birgit Stolt, a German language educator, commented at the 1976 IRSCL (the International Research Society for Children's Literature) symposium that 'In the theoretical works on the subject (translation) one hardly finds anything relevant on this subject (Scolt 1978: 133)'. Similarly, the scholar Eithne O'Connell also surprisingly expressed his concern that the translation of children's literature remains largely ignored by theorists, publishers and academic institutions. This is also the case for the children's literature in China, where the adult literature has been the mainstream for thousands of years.

\section{The Development and Translation of CL in China}

The development of children's literature in China has undergone three periods, namely, CL in ancient China, CL in premodern China and CL in contemporary era. Noteworthily, 
it was not until the premodern China, especially the New Culture Movement in 1919 that the introduction and translation of children's literature became popular in the Chinese literary system. In the following section, I will respectively elaborate on the development and translation of children's literature in the three different stages.

\section{CL in Ancient China}

$\mathrm{CL}$ in ancient China is in forms of three resources in general. It existed respectively in the ancient folklores, the classical literatures and traditional enlightened reading materials (Gudai Chuantong Qimeng Duwu)

\section{CL in the Ancient Folklores}

The ancient Chinese folklores took four forms, namely, the myth, folklores, allegories, and nursery rhymes. Myth is the earliest form of folklore in China, which reflects the ancient people's using their imagination for exploring the world. Therefore, certain beliefs or world views of the people back then are reflected through myth, usually involving the supernatural beings or events. The well-known myths include, for example, Jingweitianhai (Jinwei Fills up the Sea), Yugongyishan (Yugong Moves the Mountains) and Houyisheri (Houyi Shooting the Sun) etc. They all reflect certain beliefs of the ancient people, some spirit they revered and expected to pass on to their children generation after generation.

Take Yugongyishan as an example, it is a fable about an old man named Yugong, who kept working hard to move away two big mountains in front of his house for the convenience of people to come and go. This fable reflects the spirit of determination and perseverance. Similarly, Houyisheri is a story about a young man who shot down nine suns in the sky to prevent the world from being destroyed by the scorching heat. Therefore, this fable symbolizes the spirit of bravery. 
Min GaO

Folklores in China are developed from myth. Unlike myth, however, folklores are stories about individuals with specific surnames and first names, sometimes about the famous figures in the Chinese history. Moreover, specific time, and place for the plots are usually involved.

One famous representative folklore in ancient China was Mengjiangnv Kuchangcheng (Ms. Meng Weeping on the Great Wall). It is a story occurred during the Qin Dynasty (221-207 B.C.), when the cruel emperor of Qin practiced forced recruitment to build the Great Wall. Under such circumstances, Ms. Meng's newly married husband named Fan Qiliang was caught to build the Great Wall by the government and died at the construction site. Ms. Meng wept at the Great Wall day and night and finally the Great Wall collapsed, and the body of her husband appeared. Therefore, this folklore was to criticize the cruelty of the First Emperor of Qin.

Allegories belong to folklores. They prevailed in the Spring and Autumn Period and the Warring States Period (770-221 B.C.) of China. Unlike folklores, however, the Chinese allegories aimed to serve the educational function with few words. For instance, the allegory Ba Miao Zhu Zhang (To Pull Up the Seedlings to Help Them Grow) was about a farmer who pulled up the young plants of rice to help them grow. Obviously, all the plants died at last. This story conveys the educational concept of 'haste makes waste'.

Nursery rhyme is another literary genre that belongs to the children's literature. Two representative collections of nursery rhymes are Yanxiaoshuoyu comprising 46 chants in the Ming Dynasty (1368-1644 A.D.) and Tianlaiji (Heaven Sounds Collection) in the Qing Dynasty (1636-1932 A.D.) including 48 chants. 


\section{CL in the Classical Literatures}

CL can be found in the classical Chinese poems like yong'e (Goose) written by the poet Luo Binwang when he was only seven years old, jingyesi (A Tranquil Night) written by Li Bai and chunxiao (A Spring Morning) by Meng Haoran. These are widely read poems by the Chinese children for thousands of years. The poems are used for praising the creatures of nature or expressing the homesickness of the poets.

Moreover, fairy tales for children can be found in the classical literatures. For example, a story named yexian excerpted from the fiction collection youyangzazu written by Duan Chengshi (803-863 A.D.) in the Tang Dynasty was considered the earliest fairy tales in the Chinese history. The plots yexian has much in common with the Western fairy tale Cinderella, which was written in 1697, more than 1,000 years later.

\section{CL in the Traditional Enlightened Reading Materials (Chuantongqimengduwu)}

Some of the enlightened reading materials written in the ancient China harboured the latest form of children's literature as well. The most famous one was Sanzijing, also known as Three Character Classic, possibly written by Wang Yinglin (1223-1296 A.D.) of the Song dynasty. Sanzijing is a text featuring three Chinese characters as a sentence, which was used to teach the young children the moral principles, science, daily life, and the history of China etc.

In the Ming Dynasty (1368-1644 A.D.), a representative children's reading material is called Youxueqionglin (The Children's Knowledge Treasury). Co-authored by Cheng Dengji, Qiu Rui, and Zou Shengmai, this book provided an encyclopaedic overview of all aspects of nature and life, from famous figures in history, astronomy and geography, custom 
Min Gao

and rites, clothing, food, to palaces, jewelleries, birds, animals, flowers and trees etc.

Dizigui (Disciple Gauge) is another classical enlightenment material written by Li Yuxiu (1647-1729), an educationalist in the Qing Dynasty of China. The literary work comprises 360 sentences with 1,080 Chinese characters all together. Like Sanzijing, Diziguialso features the three-character sentences to regulate the life of children. It mainly promoted the Confucian concepts like benevolence, honesty, filial piety etc.

To conclude, although there was no such concept of CL in ancient China, it has taken several original forms, existing in myth, folklores, fables, nursery rhymes, the classical poems, literatures and the enlightened reading materials for children. The previous forms of CL, evidently, were more often passed on orally to children from the old generations than being read in written forms.

Based on the analysis of the examples, it is not difficult to find that most $\mathrm{CL}$ in the ancient China served to fulfil the educational function, be it to teach children to appreciate nature, to learn the spirit of the legendary heroes, to get along with their family members like siblings, their parents, the strangers or even how to behave properly in society.

\section{CL and its Translation in the Premodern China (Jindai Zhongguo) (1840-1949)}

\section{CL in the Late Qing Dynasty}

Although China is renowned for its literary heritage, it was not until the late Qing Dynasty (1840-1911) that Children's literature established itself as an independent subdivision of the Chinese literature (Zhang 2018)'. During this period, following the concept of 'Learning from the West' by the ruling class, the European Children's literary works were introduced and translated by the Chinese scholars and 
translators, which included the Anderson (Ye 1990) and Grimm's Fairy Tales ( Zhou 1903), Daniel Defoe's Robinson Crusoe (Shen 1902), and the Arabian Nights (Zhou 1903) etc.

It is worth mentioning that children's literature during this period was actually translated more for adults than for children as the intended audience. Such functions as education or entertainment are generally neglected. The main purpose for the translation in this period is merely for bringing in the socalled 'advanced thoughts' from the West (Wang 1987: 74). To serve the political agenda, the approaches used for the translation of children's literature were adaptations or rewritings based on the need of the national situations. As a result, most of the translations turned out to be adapted or compiled translations with neither approaching the source texts nor the target texts.

In 1908, the first collection of fairy tales (Tonghua) edited by Sun Yuxiu (1903-1936) was published by Shanghai Commercial Press, symbolizing the earliest children's reading materials (Zhu 2013: 117). Over the following 15 years from 1908 to 1923, three collections of tonghua were issued. Among the 102 works included in the collection, however, two thirds were translated from other languages while the remaining were edited stories about the Chinese history. Therefore, it was the translated literature from the West that played the dominant role in the late Qing dynasty.

\section{CL and its Translation in the New Culture Movement}

The May Fourth Movement was part of the New Culture Movement (1917-1921), which aimed to resist the traditional Confucian ideas and to rebuild the society and culture by adopting the Western concepts. One of the tasks involved in the movement was to promote the new cultures, including the introduction of the new literary genres. It is under such 
Min Gao

circumstances that the CL was born as a new genre and an independent discipline.

Unlike the late Qing dynasty, when the introduction and translation of children's literature was used to serve the political agenda, the concept regarding the definition and function of $\mathrm{CL}$ in this period underwent dramatic changes featuring child-orientedness. One of the pioneers who promoted such idea was Zhou Zuoren (1885-1967), a writer and the young brother of Lu Xun (1881-1936). As a leading figure of modern Chinese literature, Zhou firmly argued that the only standard for a good CL work lied in whether it was child-oriented or not. A lot of scholars and activists during the period followed the concept of Zhou and insisted children being the centre for CL. The main contributors included $\mathrm{Lu}$ Xun, Chen Duxiu (1979-1942), and Ye Shengtao (1894-1988) etc. The Chinese writer Ye Shengtao once commented in his work Wenyitan (on the literary arts) that the children's literature should reflect the imaginations and emotions of children. To him, any literature involving the pedagogical rules is not the real children's literature (Ye 1990: 19).

According to the scholar Zhu Ziqiang (2013: 118), it was the social context of the New Culture Movement that gave rise to the birth of the CL in China. Previously, there were two constraints which prevented the appearance of CL, one was the Confucian concept of fuweizigang (the son being absolute obedient to his father) and the other was the use of classical Chinese. To put it more specifically, the concept of fuweizigang set the father at the centre of a family, while the son or daughter taking a subordinate position. Amidst in such a social system, the children and their needs as a whole were neglected, which went against the social context which brought about the child-oriented CL. 
As for the language of traditional Chinese, Zhou thought that it cannot bear the features of children as a carrier (Zhu 118). More specifically, the ancient Chinese cannot describe the psychological activities of children. Therefore, when the New Culture Movement promoted to contradict the Confucian ideas and the traditional Chinese language, the CL emerged at the right moment.

It was the New Youth, ${ }^{2}$ a journal which initiated the New Culture Movement that first published the translated fairy tales written by foreign writers such as Anderson, Tolstoy, Sologub, to highly praise such child-oriented new literary genre (Wang 1987: 69). This journal also published the free verse in vernacular Chinese written by such writers as Lu Xun, Hu Shi (1891-1962), Zhou Zuoren and Liu Bannong (1891-1934) etc.

To resist the Confucian ideas and the old literary forms, the intellectuals in the May Fourth Movement advocated learning from the West in terms of the literature. Therefore, the translation of the foreign literatures had played a significant role in the introduction of new literature. Accordingly, large amounts of children's literature from the West were translated into Chinese during this period.

However, unlike the rewritings in the translation of children's literature in the late-Qing dynasty, the child-oriented concept in this period determined the use of literal translation. Many translators retranslated some children's literature which had been translated before through the approach of rewriting or adaptation. The retranslations were done based on the demand

${ }^{2}$ New Youth, a magazine started by the intellectuals Chen Duxiu, Li Dazhao, Hushi, and Lu Xun to encourage the youth to undertake the literary and cultural revolution so as to rejuvenate the Chinese nation. It is the magazine that first initiated the New Culture Revolution to resist the Confucian ideas and the traditional Chinese language. The magazine also played an important role in the May Fourth Movement. 
and cognition level of children instead of the need of the nation. For example, Zhou Zuoren retranslated one of the Anderson's fairy tales into Huangdidexinzhuang (the Emperor's New Clothes) previously translated by Liu Bannong in 1914. Likewise, Jonathan Swift's Gulliver's Travels previously translated by Lin Shu (1852-1924) in the late Qing Dynasty as Haiwaixuanqulu was retranslated as Geliefoyouji ${ }^{3}$. Some other literary works like Alice's Adventures in Wonderland, and the Adventures of Pinocchio were retranslated as well in this period.

Mao Dun (1896-1981), a famous Chinese writer, once commented on the phenomenon of retranslation in this period by saying that 'the children's literature movement in the May Fourth Period was either to retranslate the literary works edited by Mr. Sun Yuxiu or to introduce the fairy tales not being translated before through adopting the method of literal translation' (Wang 1987: 74).

Zhou Zuoren, as one of the main contributors of children's literature, translated a lot of children's literature in the period as well. These works include Kongdagu (Tolstoy's the Empty Drum), Anderson's Maihuochai de Xiaonvhai (the Little Match Girl), the Japanese writer Kunikida Doppo's Shaonian de Beiai (the Sadness). Shen Yanbing (1896-1981) translated Maupassant's Simon's Papa (Ximen de baba). Fairy tales written by Oscar Wilde including the Fisherman and his Soul (Yufu Yu Tadehun), the Nightingale and the Rose (Yinger Yu Meigui), the Happy Prince (Xingfude Wangzi), the Selfish

\footnotetext{
${ }^{3}$ Lin Shu, with the courtesy name of Lin Qinnan, was a famous translator and man of letters in the premodern China. He was most renowned for translating the foreign literatures to the Chinese readers in spite of his ignorance of foreign languages. He usually collaborated with the oral interpreters for the translation of the literary works from the other countries.
} 
Giant (Liji de Juren), the Star Child (Xinghaizi) were translated and published by Shanghai Taidong Publishing Press in 1922 as a collection named Fairy Tales of Oscar Wilde (Wangerde Tonghua).

Moreover, the writer Zheng Zhenduo (1898-1958) and his wife Gao Junzhen (1901-1985) collaborated to translate the fairy tale collection the Swan (Tian'e). This collection of fairy tales was published in 1925, including the translations of Russian allegories like the Ass and the Nightingale (IÜzi Yu Yeying), Swan, Pike and Crawfish (Tian'esuo Yu Yupangxie), the Box (Xiangzi), and the Oak and the Reeds (Xiangshu Yu Luwei). Likewise, Lu Yan (1901-1944) translated the Russian fairy tales like Little Mosquito (Xiaowenzi), the Last Fly (Zuihoude Cangying), Time for Bed (Shi Shuijiao De Shihoule).

The introduction and translation of large amounts of children's literary works from abroad inspired the domestic writers. Children's poetry created in this period included the Children's Song (Er'ge) written by Zhou Zuoren, the Son and the Shadow (Er He Yingzi) written by Ye Shengtao, and Gu Jiegang's (1893-1980) Eating Fruits (Chiguoguo). Moreover, Ye Shengtao wrote his famous fairy tale the Straw Man (Daocaoren) and got it published in 1923.

It can be seen that the main developing trend of the CL during the New Culture Movement was either to (re)translate the foreign literary works by literal translation or to edit and write children's literature by the domestic writers.

\section{CL and its Translation in the Contemporary Era}

Since the May Fourth Movement in 1919, the introduction and translation of children's literature maintained an upward trend, especially after the founding of the People's Republic of China. However, this situation changed later during some special periods like the Cultural Revolution, when the 
Min Gao

translation of children's literature stagnated due to the unfavourable domestic and international political environment.

To be more specific, the political struggles between the ruling class in China and its adverse diplomatic relations with other Countries across the world insulated China from all the cultural communications including the translation activities. It is recorded that only four foreign literature works were translated into Chinese for internal circulation within the Party during this period. No translations from/into Chinese were publicly published. Although the Reform and Opening Up policy since 1978 helped ameliorate the condition, the translation of children's literature was far less flourishing than ever before. This condition did not change dramatically until the $21^{\text {st }}$ century, which served as a milestone for the introduction and translation of foreign children's literary works.

A report from the authoritative electronic journal issued by the State Administration of Press, Publication, Radio, Film, and Television of the People's Republic of China confirmed the trend. During the 10 years from 1995 to 2004, the number for the imported children's literary books, many of them were translations, rose from 1664 to 10040 , with an annual increase rate of $25 \%$. These imported books accounted for only $2.29 \%$ of the total number of the children's literary works in China in 1995. However, the percentage went up significantly to $20.5 \%$ in 2004. According to the China Publishers Yearbook, the number for the imported children's books increased from 39,120,000 to 487,480,000 between 2005 and 2015, in spite of some slight fluctuations during certain years.

Based on the relevant statistics, there are 581 publishing houses in China and 523 of them publish the children's literary works. The new century saw the rapid development of the children's literature in China, compared with the adult 
literature. Although the children's literature remained in a heated state in the market, it is still in a peripheral position in the circle of academia (Li 2012: 30).

\section{Problems Existed in the Translation of $C L$ in China}

The number of the importation and translation of children's books rose dramatically in recent years, but there are some problems in terms of the translation quality. The Chinese scholar Chen Cheng (2015: 264) attributed the problem to the Chinese publishers' seeking economic profits. Other scholars Sun and Shi (2012: 24) expressed the same viewpoint in their collaborated article with further explanations: 1) The publishers are unwilling to employ the professional and renowned translators out of consideration for reducing the translation cost. Instead, they would rather choose less professional translators with lower quotations; 2) The publishers require the translation of children's literary books completed as soon as possible in order to seize the market share and keep ahead of the competition with their counterparts. As a result, the source languages cannot be well processed, resulting in too many literal translations.

Other problems occurred as well. For example, cultural-related items, dialects or slangs which pose great difficulties in the process of translation cannot be appropriately dealt with. Moreover, the language style of the translated texts is not in line with the children's literary language and is too insipid to attract the attention of the child readers (Chen 2015: 264).

\section{Conclusion}

This paper provides a literature review for the development of children's literature as well as its translation in China. Despite the peripheral position of children's literature in the Chinese literary system, it has undergone significant changes all the way through the ancient China to the premodern period and 
Min GaO

finally to the contemporary era. However, it was not until the period of premodern China that the translation of children's literature started.

There are problems existed in the translations of CL. The translation quality is unsatisfactory, as revealed in the comments of the parents on the website of the main online book vendors in China. The cultural-related items are not properly dealt with in the process of translation and the language style of some translations is not in line with that of the children's cognition, which, as a result, fails to appeal to the child readers. The existent phenomenon is primarily due to the unprofessional translators employed by the publishers to reduce the cost of translation. Therefore, some measures should be taken to help regulate the translation of CL in China.

\section{References}

CHEN,

CHENG. 2015.

世纪我国儿童文学出版的现状与对策研究 (The Status

Quo of China's Publishing Industry for the Translation of Children's Literature in the $21^{\text {st }}$ Century). Home Drama 8. 263-265.

LI, DONGHUA. 2012. 沸腾的边缘: 新世纪的中国儿童文学

(On the Heating Edge: Children's Literature in the New Century). Southern Cultural Forum 2. 30-34.

SHEN, ZufEN. 1902. Robinson Crusoe. Beijing: Guangming Publishing House.

StOlT, BIRGIT. 1978. How Emil Becomes Michel: On the Translation of Children's Books. Stockholm: Almqvist and Wiksell.

Sun, SHIQUAN, and SHI ChUnRANG. 2012. 儿童文学翻译出版的怪现状 (The Strange Phenomena for 
the Translation and Publishing of the Children's Literature in China). Editorial Board 12. 23-25.

WANG, QUANGEN. 1987. 论五四时期的中国儿童文学 (The Chinese Children's Literature in the New Fourth Movement). Journal of Southwest China Normal University 4.69-77.

Ye, ShengtaO. 1990. 叶圣陶集第九卷: 文艺谈 (On Literary Arts: The Ninth Volume of Ye Shengtao's Collected Essays). Nanjing: Jiangsu Education Publishing House.

$\begin{array}{lll}\text { ZHANG， JIANQING. } & 2008 .\end{array}$

\section{晚清儿童文学翻译与中国儿童文学之诞生--}

译介学视野下的晚 清儿童文学研究 (The Translation of Children's Literature in the Late Qing Dynasty and the Birth of the Chinese Children's Literature: A Research on the Children's Literature in the Late Qing Dynasty from the Perspective of Medio-translatology). Diss. Shanghai: Fudan University.

ZHOU, GuISHENG. 1903. 新庵谐意 (Humorously Translated

Stories in Xin'an). Shanghai Qinghua Book Company.

ZHU, ZIQIANG. 2013. 论新文学运动中的儿童文学

(Children's Literature in Neo-Literature Movement).

Journal of Shanghai Normal University 4.116-121. 